OPEN ACCESS

Edited by:

Enric Gisbert,

Institute of Agrifood Research and Technology (IRTA), Spain

Reviewed by:

Nelly Tremblay,

Maurice Lamontagne Institute,

Fisheries and Oceans Canada,

Canada

Diego Castejón Bueno, Centro Interdisciplinar de Investigação

Marinha e Ambiental da Madeira

(CIIMAR-Madeira), Portugal

*Correspondence:

Marco Fus

marco.fusi@kaust.edu.sa

Folco Giomi

folcog@gmail.com

Specialty section:

This article was submitted to

Aquatic Physiology,

a section of the journal

Frontiers in Marine Science

Received: 30 August 2021 Accepted: 04 November 2021

Published: 26 November 2021

Citation:

Fusi M, Daffonchio D, Booth J and Giomi F (2021) Dissolved Oxygen

in Heterogeneous Environments

Dictates the Metabolic Rate

and Thermal Sensitivity of a Tropical

Aquatic Crab.

Front. Mar. Sci. 8:767471.

doi: 10.3389/fmars.2021.767471

\section{Dissolved Oxygen in Heterogeneous Environments Dictates the Metabolic Rate and Thermal Sensitivity of a Tropical Aquatic Crab}

\author{
Marco Fusi ${ }^{1,2 *}$, Daniele Daffonchio ${ }^{2}$, Jenny Booth ${ }^{3}$ and Folco Giomi ${ }^{4 *}$ \\ ${ }^{1}$ Edinburgh Napier University School of Applied Sciences, Edinburgh, United Kingdom, ${ }^{2}$ Red Sea Research Center (RSRC), \\ King Abdullah University of Science and Technology (KAUST), Thuwal, Saudi Arabia, ${ }^{3}$ Coastal Research Group, Department \\ of Zoology and Entomology, Rhodes University, Makhanda, South Africa, ${ }^{4}$ Independent Researcher, Padua, Italy
}

Oxygen availability, together with water temperature, greatly varies in coastal habitats, especially in those characterized by elevated primary production. In this study, we investigate the combined role of dissolved oxygen and temperature on the thermal physiological response of the mud crab Thalamita crenata living in an equatorial system of coastal habitats. We sampled temperature, oxygen and salinity in T. crenata habitats, mangrove creeks and fringes and seagrass meadows, at Gazi Bay (Kenya). We found that seagrass meadows exhibited higher temperature and oxygen saturation than the mangrove habitats during the day, creating conditions of oxygen supersaturation. By investigating the effect of different levels of oxygen saturation on the thermal response of $T$. crenata, we demonstrated that the respiratory physiology of this ectotherm has a pronounced resistance to heat, directly influenced by the amount of dissolved oxygen in the water. Under low oxygen saturation levels, the mud crab significantly reduced its metabolism, becoming temperature-independent. This result shows that aquatic species can modulate their thermal response in a stringent dependency with water oxygen saturation, corroborating previous findings on the thermal response of $T$. crenata under supersaturation. This contribution provides further support for the need to adopt an ecologically-relevant approach to forecast the effect of climate change on marine ectothermal species.

Keywords: coastal habitats, mangrove, seagrasses, oxygen saturation, temperature-independent metabolism, Thalamita crenata, thermal sensitivity

\section{INTRODUCTION}

Temperature-driven community changes in the ocean occur as a result of the effect of global warming on the physiological tolerance and performance of marine species (Antão et al., 2020). These changes may be exacerbated by the predicted progressive oxygen loss in seawater caused by increasing water temperature and from the accumulation and retention of heat in seawater masses (Breitburg et al., 2018). Although the long term trends and global averages of oxygen loss (predicted to be about $2 \%$ by the end of the century) and temperature increase have drawn intense recognition, the high daily variability of these environmental parameters have received less attention (Craig and Hayward, 1983; Andersen et al., 2017; Giomi et al., 2019; Altieri et al., 2021). At a fine spatial scale, highly productive coastal habitats undergo acute fluctuations of dissolved 
oxygen from under- to supersaturation which are primarily determined by water temperature and sunlight (Giomi et al., 2019). Coastal ecosystems are often characterized by mosaics of habitats where acute environmental fluctuations are important drivers of the tolerance and adaptability of aquatic fauna. Indeed, coastal organisms evolved under highly variable oxygen saturation and temperature conditions, such as those occurring in seagrass meadows, coral reefs, seaweed prairies, and/or highly productive microbial mats associated with mangroves (Dubuc et al., 2019; Giomi et al., 2019).

The influence of characteristic environmental heterogeneity in mangrove forests, specifically temperature and oxygen fluctuation, on the metabolism, physiology and behavior of the resident aquatic ectotherms is poorly understood. Like in other highly productive ecosystems, dissolved oxygen in mangroves is the most variable parameter influenced by the interaction of abiotic variables and the autotrophic photosynthetic cycle, resulting in a massive production during the day followed by the consumption by respiration during the night (Mattone and Sheaves, 2017).

In aquatic ectotherms, heat tolerance is tightly linked to oxygen availability (Das and Stickle, 1993; Pörtner, 2010; Ern et al., 2015); generally, during warming, the circulatory and ventilatory systems fail to sustain oxygen demand with a cascading effect on all the higher functions (e.g., muscular activity, energy intake, homeostasis and behavior). The thermal tolerance window of aquatic ectotherms is therefore susceptible to high temperatures because heat drives the onset of the mismatch between oxygen requirements and the species inability to sustain the elevated metabolic demand (Sokolova et al., 2012). Conversely, the greater oxygen availability associated with oxygen supersaturation provides the required surplus to sustain the increased metabolic demand dictated by high temperatures (Giomi et al., 2019; Booth et al., 2021). Therefore, the thermal sensitivity of aquatic ectotherms seems to be finely modulated in heterogeneous environments likely because oxygen, that generally varies in phase with temperature, drives the consumption rate and energy expenditure (Brill et al., 2015; Booth et al., 2021).

In this study, we investigate the thermal response of a model ectothermal marine species living in tropical coastal ecosystems, where the habitats are subjected to ample and regular daily oxygen fluctuations. We studied one of the most common tropical coastal ectotherms, the swimming crab Thalamita crenata, under the different levels of oxygen saturation and thermal regimes that occur in the different habitats it colonizes. The working hypothesis of our study is that the metabolic levels of such ectothermal species is not only temperature-driven, but are adjusted in response to the available dissolved oxygen.

\section{MATERIALS AND METHODS}

\section{Study Area}

Gazi Bay is a semi-enclosed, shallow bay, located about $40 \mathrm{~km}$ south of Mombasa, Kenya $\left(4^{\circ} 22^{\prime} \mathrm{S}, 39^{\circ} 30^{\prime} \mathrm{E}\right)$. The climate of the Kenyan coast is typically monsoonal, being influenced by the moist southeast monsoon from March to September and the dry northeast monsoon from October to March; rain occurs in March to May and, to a lesser extent, October to November. Total annual precipitation fluctuates between 1,000 and 1,600 $\mathrm{mm}$. Air temperatures are high (average of $27-28^{\circ} \mathrm{C}$ ) with minimal seasonal variation, and relative humidity is around $95 \%$ due to the proximity of the sea (Kitheka et al., 1996).

Gazi Bay is a well-connected mosaic coastal ecosystem composed of three main microhabitats: the mangrove forest, the seagrass meadows and the (seaward) coral reefs (Figure 1). The mangrove forest surrounds the northern shores of the bay covering an area of approximately $6.61 \mathrm{~km}^{2}$ (Matthijs et al., 1999). The geomorphology of the Gazi Bay mangrove forest comprises mangrove creeks, characterized by a dense plant canopy covering sediment carved by a dense and dendritic system of inlets. The mangrove fringes have a more open canopy, forming an ecotone that fades into the seagrass meadows (Figure 1). The mangrove forest receives limited freshwater and sediment inputs. Tidal range is about $1.4 \mathrm{~m}$ during neap and $4 \mathrm{~m}$ during spring tides, generating significant flows across the bay. Water in-welling occurs from the large Thalassodendron dominated seagrass meadows, lying southward and seaward of the mangroves, with significant retention of ebb currents by the mangroves (Kitheka et al., 1996).

\section{Environmental Parameters}

During the research period (October-December 2011) we monitored the three habitats by measuring the temperature and oxygen content at high tide during spring tide when the animals are more active due to the higher tidal excursion (Vezzosi et al., 1994). Specifically, we repeatedly checked for the occurrence of specimens of $T$. crenata and collated the environmental parameters in their surrounding microhabitats. We measured oxygen saturation and temperature using the multi-probes HANNA HI-9147-04 and salinity using a salinity refractometer. These measurements were taken during low spring tide, between 12:00 and 13:00 h.

\section{Model Species}

We studied the swimming crabs (Decapoda: Portunidae) T. crenata (Rüppell, 1830) as model aquatic species, one of the most abundant macrobenthic species, widely distributed throughout the Indo-Pacific Ocean and Red Sea coastal waters. T. crenata is a main predator and is considered a keystone species (Atwood et al., 2015). Thalamita crenata in Gazi Bay occurs in all the three habitats monitored in this study (mangrove forests, mangrove fringe, and seagrass meadows), but also occurs on rocky shores and coral reefs (Fishelson, 1971; Cannicci et al., 1996; Vannini and Innocenti, 2000).

During October and November 2011, we collected a total of 32 males $T$. crenata individuals, of similar carapace width (51 $\pm 6 \mathrm{~mm}$ ), from the coastal area of Gazi Bay. Animals were immediately transported to the KMFRI labs in Gazi village and acclimated for $12 \mathrm{~h}$ in aerated filtered seawater (35 ppt, $27 \pm 0.5^{\circ} \mathrm{C}$ ) at $100 \%$ oxygen saturation, following the procedures described in Fusi et al. (2017). 


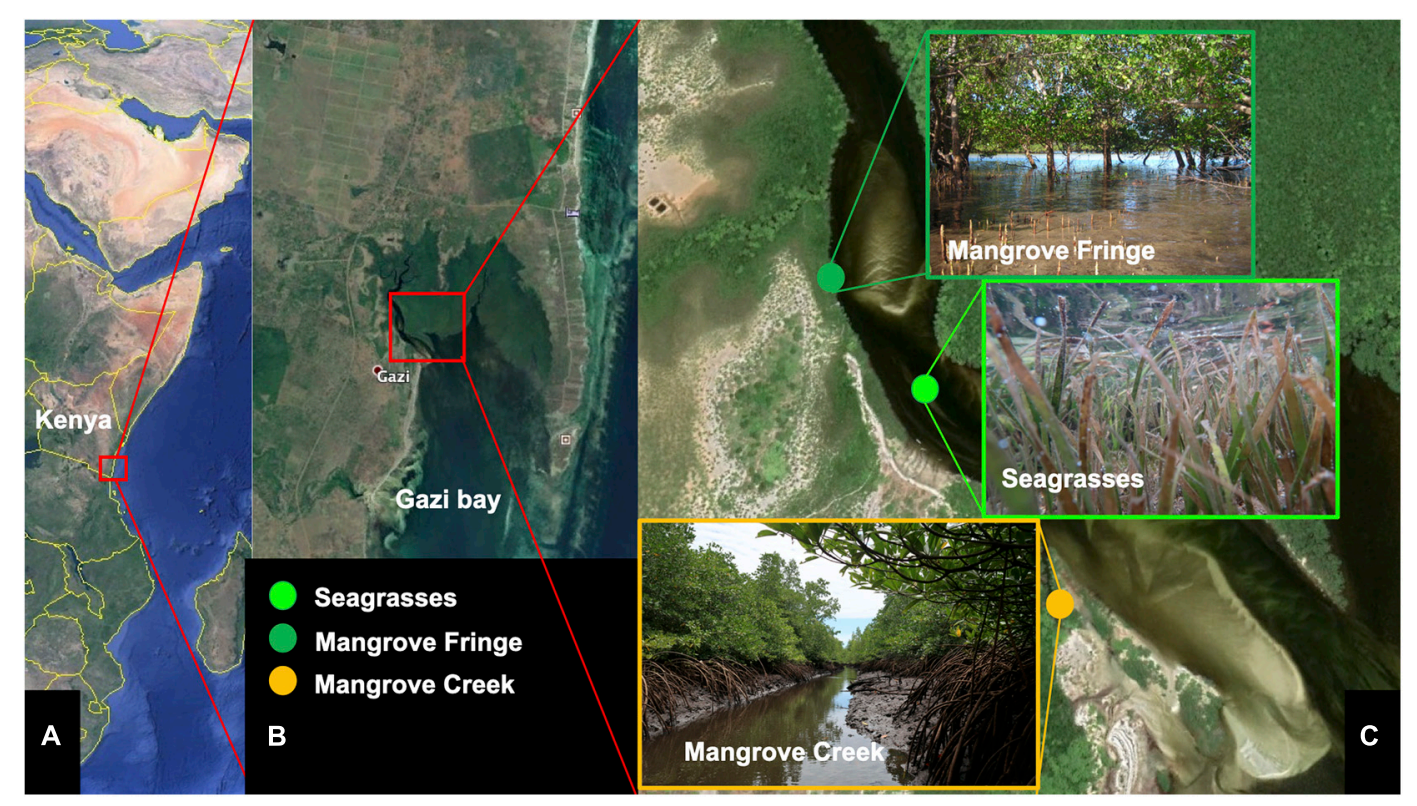

FIGURE 1 | The equatorial study site was Gazi Bay (Kenya) (A) with three habitats where the study species Thalamita crenata occurs, (B) the mangrove fringe opening onto the main channel of the forest, the seagrasses growing in the channel and the seaward subtidal area and the mangrove creek (C). Photo Credit in panel (C): MF

All experiments were conducted in accordance with the Guidelines for the Treatment of Animals in Behavioral Research and Teaching from the Buchanan et al. (2012). Animals used in the experiments were also maintained and treated in compliance with the guidelines specified by the Kenyan authorities. In addition, all necessary permits were obtained, and all experiments and procedures were approved by Kenyan authorities.

\section{Metabolic Oxygen Consumption}

Rates of oxygen consumption $\left(\mathrm{MO}_{2}\right.$ hereafter $)$ were measured in darkened Perspex chambers placed in a temperature-controlled water bath. An oxygen sensor (Sensor Type PSt3 PreSens, Regensburg, Germany), glued to the inner wall of the chamber and connected to a single channel oxygen transmitter Fibox 3 (PreSens, Regensburg, Germany) through an optical SMA fiber, was used to measure the partial pressure of oxygen in air and water. Data were recorded using FibSoft v.1.0 software (Loligo Systems ApS). Before starting the experiment, sensors were calibrated in air-equilibrated seawater (100\% saturation) and in sodium thiocyanate saturated solution in seawater $(0 \%)$. The limited movement of individuals was adequate to ensure mixing of the water and $\mathrm{MO}_{2}$ was determined by measuring the linear decline in oxygen saturation. An empty chamber was run as a control during each trial to account for background oxygen depletion, which was less than $2 \%$ of crab $\mathrm{MO}_{2}$. Before starting the temperature ramp, individuals were placed in the chambers and allowed to recover from handling stress overnight at $29 \pm 0.5^{\circ} \mathrm{C} . \mathrm{MO}_{2}$ was determined over the temperature range from 29 to $40^{\circ} \mathrm{C}$, within the extremes of the physiological range of this species in the study area. The temperature increase rate was $1^{\circ} \mathrm{C} \times \mathrm{h}^{-1}$. At the end of the experiments, each animal was weighed and its volume calculated by immersion in a graduated cylinder to record the water displacement. All experiment durations were less than $24 \mathrm{~h}$ to minimize interference of disturbing factors such as starvation on metabolic rate (Terblanche et al., 2011).

The $\mathrm{MO}_{2}$ was measured at full oxygen saturation $(100 \%$ air saturation) and oxygen undersaturation (20\% air saturation). Exposure to oxygen undersaturation was achieved by collecting seawater with low oxygen saturation from the mangrove lagoon during night time (saturation was checked with an oxygen probe). Individuals where acclimated for $2 \mathrm{~h}$ in the hypoxic conditions, before starting the temperature ramp. To compare the effect of oxygen supersaturation on the metabolic rate of $T$. crenata, we retrieved $\mathrm{MO}_{2}$ data of from Giomi et al. (2019). Although the different methodological procedure in Giomi et al. (2019), data at $100 \%$ of oxygen saturation were comparable and therefore we use the supersaturation response as term of comparison to show the possibility of $T$. crenata to increase its metabolic rate under oxygen supersaturation. However, we acknowledge the possible bias and caveats in this comparison due to the different location and environmental and lab condition.

\section{Aerobic Performance}

Oxygen partial pressure in arterial and venous haemolymph $\left(\mathrm{hPO}_{2}\right)$ was measured with fiber-optic oxygen microsensors (PreSens $\mathrm{GmbH}$ ) connected to an oxygen meter (Microx-TX, PreSens $\mathrm{GmbH}$ ) with integrated signal processing software. Sensors were calibrated before the experiment using a twopoint calibration in oxygen-free (addition of sodium dithionite) and air-saturated seawater. Animals were acclimated overnight at $29^{\circ} \mathrm{C}$ and $\mathrm{hPO}_{2}$ was estimated between 29 and $40^{\circ} \mathrm{C}$ 


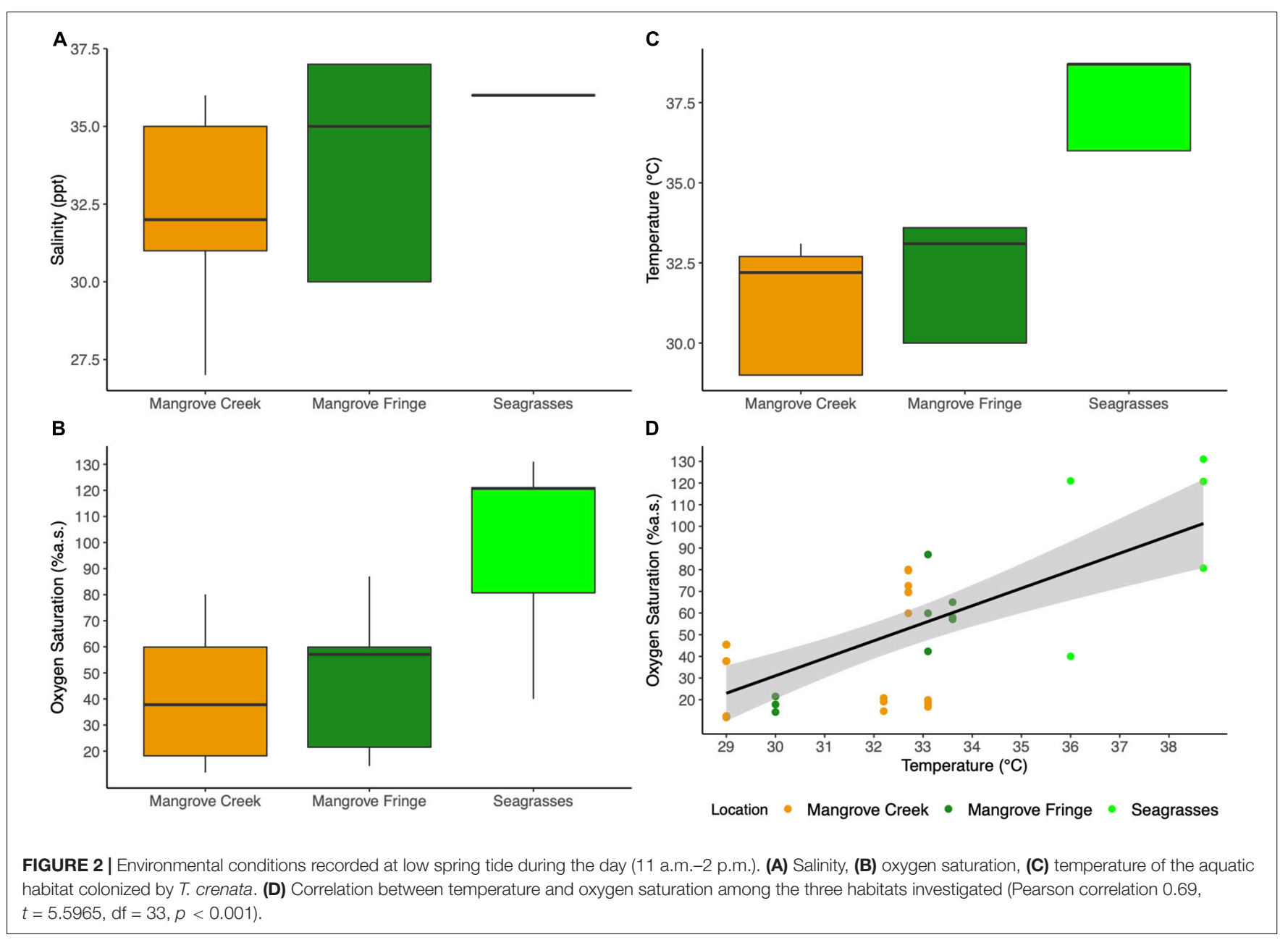

(accuracy $\pm 1^{\circ} \mathrm{C}$ ), using the thermal ramping protocol described for the $\mathrm{MO}_{2}$ experiment.

To measure arterial $\mathrm{PO}_{2}$, haemolymph was sampled from a hole $(0.2 \mathrm{~mm}$ diameter $)$ drilled through the carapace over the pericardial sinus following Frederich and Pörtner (2000). Venous haemolymph was withdrawn from the sinus below the arthrodial membrane, at the base of the fourth or fifth pereiopod (Pörtner and Giomi, 2013). In both cases, $20 \mu \mathrm{l}$ of haemolymph were collected through capillary action using a manually sharpened Pasteur pipette in which the oxygen sensor was previously inserted and positioned close to the tip.

\section{Statistical Analysis}

For analysis of $\mathrm{MO}_{2}$ and $\mathrm{PO}_{2}$, the null hypothesis of no difference for specimens exposed to different seawater oxygen levels [fixed and orthogonal explanatory variable; three levels: low oxygen saturation (20\% of oxygen air saturation), full saturation (100\% of oxygen air saturation), super saturation (140\% of oxygen air saturation)], across different temperatures (continuous explanatory variable) was tested using a mixed linear model with the lmer package in $\mathrm{R}$ (Bates, 2015). Measurements across the temperature ramp were made on the same individuals, thus they were not independent. Consequently, we treated
Individual ID as a random factor in the mixed model to account for multiple observations (Bates, 2015; Fusi et al., 2017).

To estimate the breakdown point of the arterio-venous differences in $\mathrm{PO}_{2}$, a stepwise regression was performed using the R package "segmented."

To test for statistical differences in the environmental parameters (Salinity, Temperature, and Oxygen) among the habitats studied, we used an analysis of variance. Log transformation was used for normality and homoscedasticity. All the analyses were performed using R (R Core Team, 2017). Data are presented as mean \pm standard error.

\section{RESULTS}

\section{Environmental Parameters}

Salinity was significantly different among the three sites at low tide, with the mangrove creek showing an average salinity of $32.1 \pm 0.6 \mathrm{ppt}$ increasing to $35 \pm 0.6 \mathrm{ppt}$ in the fringe and up to $36 \pm 0.1 \mathrm{ppt}$ in the seagrasses meadows (Anova, $F_{2,32}=4.626$; $p<0.05$; Figure 2A). Oxygen saturation was significantly higher in the seagrasses, reaching levels of supersaturation up to $130 \%$, while oxygen levels in the mangrove fringe and mangrove creek 


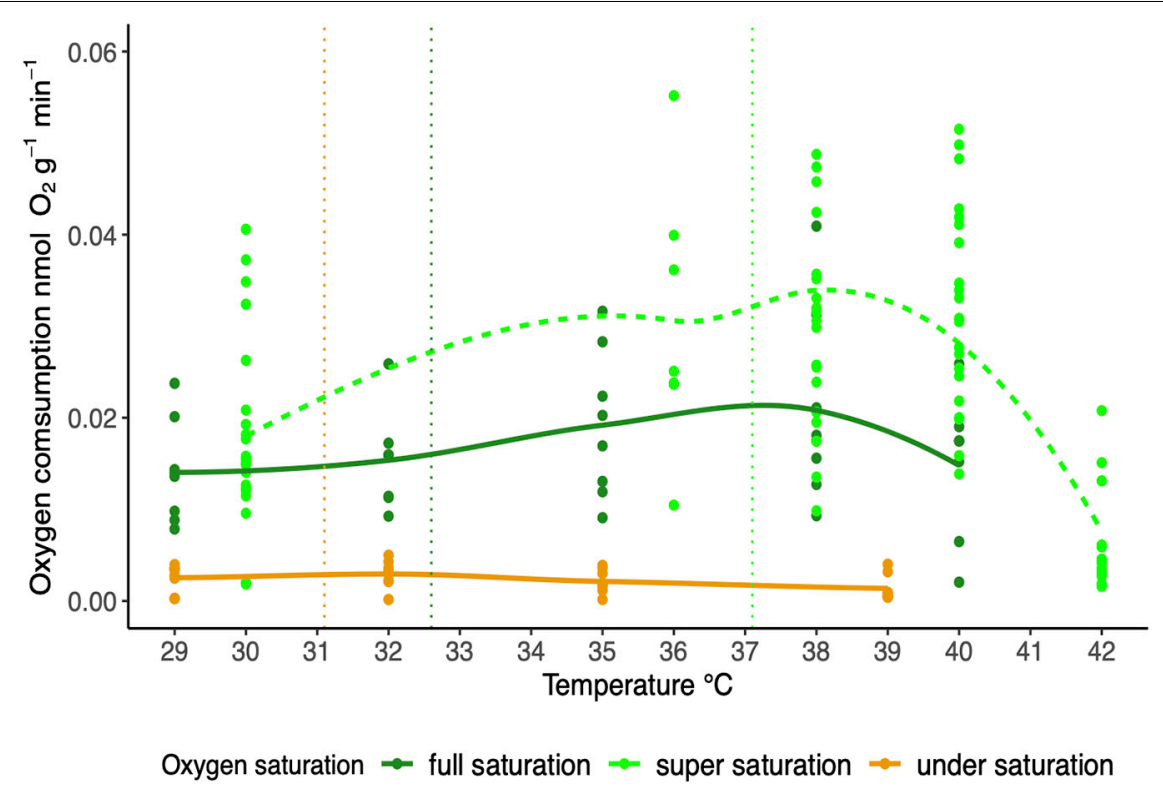

FIGURE 3 | Oxygen consumption rate of T. crenata along a temperature ramp under different conditions of water oxygen saturation: super saturation [140\%, dash line: data from Giomi et al. (2019), $n=23$ ], full saturation (100\%; solid line, $n=8$ ), under saturation (20\%; solid line, $n=8$ ). The vertical line refers to the average water temperature recorded in the mangrove creek (yellow), mangrove fringe (dark green) and seagrasses meadow (green).

were between 40 and $50 \%$, respectively (Anova, $F_{2,32}=10.22$; $p<0.001$; Figure 2B). Water temperature measured during the middle of the day was consistently higher in seagrasses meadows $\left(37.6 \pm 0.6^{\circ} \mathrm{C}\right)$ compared to the other two habitats $\left(31.1 \pm 0.4^{\circ} \mathrm{C}\right.$ in the mangrove creek and $32.6 \pm 0.5^{\circ} \mathrm{C}$ in the mangrove fringe; Anova, $F_{2,32}=26.88 ; p<0.001$; Figure 2C). A significant positive relationship between temperature and oxygen was found across the habitats (linear model, $F_{1,33}=31.32 ; p<0.001$; $R^{2}=0.47$; Figure 2D), while there were no significant trends among oxygen and salinity.

\section{Metabolic Oxygen Consumption}

We detected a significant effect of temperature (GLM, $F_{1,158}=5.7486 ; p<0.05$ ) and oxygen saturation (GLM, $F_{1,158}=94.3724 ; p<0.0001$ ) on $\mathrm{MO}_{2}$ (Figure 3 ). The temperature-dependent increase of $\mathrm{MO}_{2}$ was recorded when animals were exposed to full (100\%) oxygen saturation (GLM, $\left.F_{1,37}=3.17 ; p<0.01\right)$, but not to low saturation $(20 \%)$ conditions (GLM, $F_{1,30}=1.99 ; p=0.17$ ). For comparison, the data for $T$. crenata exposed to oxygen supersaturation from Giomi et al. (2019) are shown (Figure 3).

\section{Aerobic Performance}

The oxygen dissolved in the venous and arterial haemolymph of animals exposed to full saturation (100\%) differed significantly along the temperature $\operatorname{ramp}\left(\mathrm{GLM}, F_{1,75}=27.47 ; p<0.001\right.$; Figure 4A). Arterial haemolymph was consistently significantly higher than venous haemolymph up to $38^{\circ} \mathrm{C}$, above which dissolved oxygen dropped to similar levels (GLM, $F_{1,75}=24.52$; $P<0.001$; Figure 4A), both falling close to $0 \%$ at $40^{\circ} \mathrm{C}$. The stepwise regression (Figure 4B) of the arteriovenous differences in $\mathrm{PO}_{2}$ indicated a breakdown point at $38.23^{\circ} \mathrm{C}$, beyond which the oxygen content in the haemolymph dropped down toward $0 \%$. At temperatures below this breakpoint (from 29 to $38^{\circ} \mathrm{C}$ ), the haemolymph oxygen content remained consistently stable while further warming determined a significant reduction of the haemolymph oxygen content (Estimated slope-4.8895; $t=-2.456$; $p<0.05)$.

\section{DISCUSSION}

\section{Environmental Heterogeneity}

The environmental conditions that aquatic animals experience are determined by various factors that are dependent on the habitat colonized. In tropical vegetated coastal ecosystems, like mangrove forests and seagrasses meadows, tidal cycles are one of the main driving forces that drive the changes of abiotic parameters (Mattone and Sheaves, 2017).

The mangrove and seagrass meadows, forming a coastal mosaic pattern of habitats in Gazi Bay, are characterized by differing conditions in terms of temperature, salinity, and oxygen. In the mangrove creeks, water temperature is lower because the dense canopy cover reduces solar radiation; in the mangrove fringe, canopy cover is less dense and so water receives more solar radiation; while seagrasses meadows are in waters exposed to full sunlight. These observations explain the positive relationship between water temperature and oxygen, since under intense solar radiation primary producers maximize their photosynthetic activity. This relationship has been previously documented in similar tropical ecosystems 


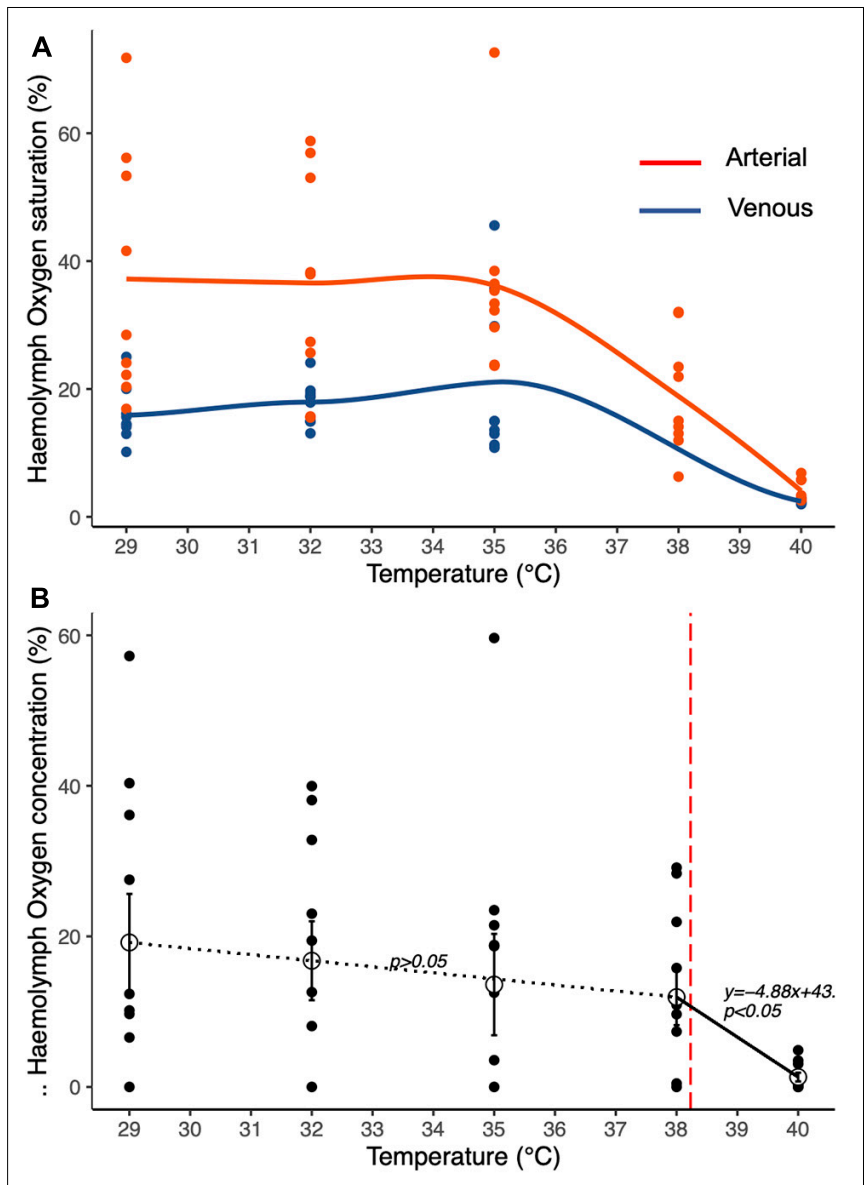

FIGURE 4 | Temperature-dependent haemolymph dissolved oxygen content of $T$. crenata during (A) water respiration at $100 \%$ oxygen saturation; red circles arterial haemolymph, blue circles venous haemolymph. (B) the arterio-venous differences in $\mathrm{PO}_{2}$ provide an indication of the relative efficiency of respiration in water. The dotted line indicates a non-significant relationship between temperature and haemolymph dissolved oxygen content, while the solid line indicates a significant reduction of haemolymph dissolved oxygen content with increasing temperatures after the estimated breakpoint at $38.23^{\circ} \mathrm{C}$ indicated by the vertical red dashed line.

(Giomi et al., 2019; Altieri et al., 2021), where temperature increase stimulates a massive production of oxygen driving conditions of supersaturation up to $300 \%$ during the day. In this study, we recorded low oxygen saturation (around 35\%) at the same time of day and same tidal conditions in the two mangrove habitats and a higher level of oxygen in seagrasses with peaks of supersaturation up to $130 \%$ (Figure 2). In mangrove creeks under closed and dense canopies the activity of photosynthetic organisms may be inhibited by solar radiation and also by the production of anti-fouling compounds such as polyphenols and tannins leached by the mangrove tree roots (Cooksey and Cooksry, 1978). In addition, the large amount of organic matter present in mangrove ecosystems can rapidly consume the oxygen in the seawater (Alongi, 1990). Conversely, the seagrasses habitat has a higher level of oxygen because photosynthesis is stimulated by higher temperatures and full exposure to solar radiation, generating oxygen supersaturation (Long et al., 2020).

\section{Flexible Metabolic Performance in Heterogeneous Environment}

Environmental variability shapes the performance and the tolerance of aquatic species (Mcmahon, 1988; Bernhardt et al., 2020; Kroeker et al., 2020). Several mangrove fishes, for example, have evolved the ability to cope with different oxygen levels in order to maximize habitat utilization (Dubuc et al., 2019). The tolerance to oxygen undersaturation is a conserved trait across different fish species that inhabit mangrove forests (Sheaves et al., 2015).

In the mosaic coastal habitat composed by coral reefs, seagrass meadows and mangrove forests $T$. crenata experiences rapid and acute fluctuations in water oxygen saturation as the result of biotic (i.e., photosynthesis) and abiotic (i.e., tides) factors (Fishelson, 1971; Cannicci et al., 1996; Vannini and Innocenti, 2000; Giomi et al., 2019). The results of physiological measurements demonstrate that $T$. crenata modifies its metabolic rate according with the seawater oxygen saturation and is able to endure acute heat events (Figure 3). Specifically, under full saturation, its metabolic rate remains stable up to $35^{\circ} \mathrm{C}$, progressively increasing till $38^{\circ} \mathrm{C}$ and subsequently drops at $40^{\circ} \mathrm{C}$. This indicates that $T$. crenata can control its metabolic rate under warming, displaying a noticeable tolerance to temperature change. This finding is corroborated by its haemolymph oxygen content that was found to be temperature-independent up to $38.2^{\circ} \mathrm{C}$, demonstrating that this water-breathing crab can efficiently extract oxygen from water even at temperatures that are critical for sympatric semi-terrestrial crab species (Fusi et al., 2015, 2017). Generally, a decrease in oxygen extraction capacity impairs metabolic rate (Sokolova and Pörtner, 2003; Booth et al., 2021), most probably due to the allocation of energy to maintenance when in a critical condition (Sokolova et al., 2012). Here, the efficient oxygen extraction from water, and supply to the tissues, explains the stable metabolic rate of $T$. crenata over a large temperature range. Similarly, although with a lower metabolic rate, the exposure to oxygen undersaturation results in a steady metabolic rate suggesting a thermally-independent hypometabolism for $T$. crenata. In ectotherms, temperatureindependent metabolism is commonly triggered under stress and can be achieved via metabolic depression (Bridges and Brand, 1980; Verberk et al., 2016; García-Rueda et al., 2021). For example, Echinolittorina malaccana living on rocky shores undergoes a degree of metabolic depression when exposed to high temperatures (Marshall and McQuaid, 2011). Similarly, the saltmarsh crustacean Sphaeroma rugicauda tends to switch to temperature-independent metabolism during exposure to high temperatures in summer months (Marsden, 1979). This strategy allows conservation of respiratory substrates/oxygen that would otherwise be used to meet elevated metabolic demands during severe thermal stress, which will likely occur if the environmental temperature exceeds the critical physiological temperature (Hui et al., 2020). The depression of metabolism in T. crenata under oxygen undersaturation naturally occurs during 


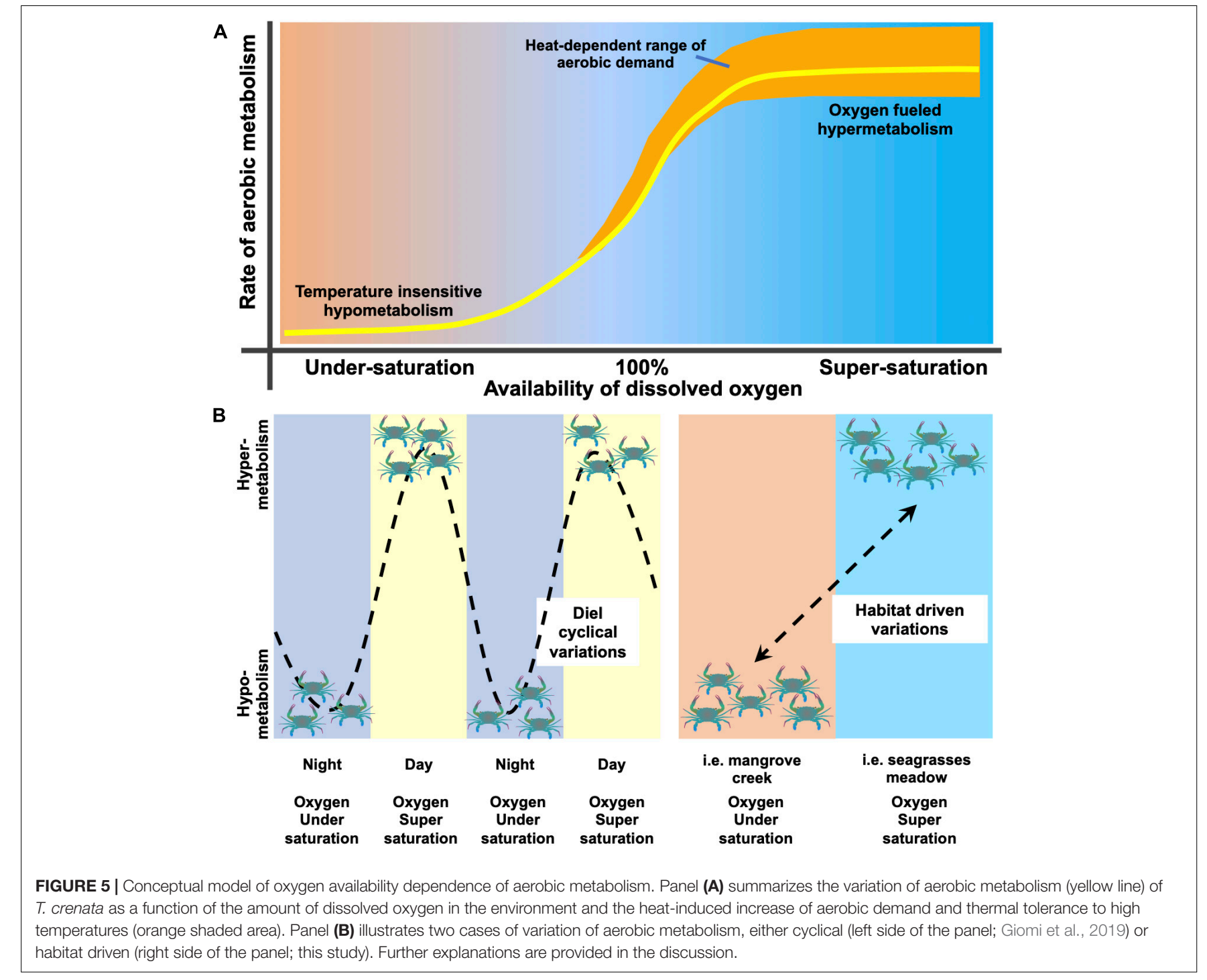

the night and is paralleled by a marked thermal insensitivity, when respiration by autotrophs reduces water oxygen saturation in mangroves, seagrasses and coral reefs (Giomi et al., 2019). Adaptation to low oxygen availability has also been recently shown in the female brooding behavior and during the early ontogeny of the Chilean kelp crab Taliepus dentatus; cyclical exposure to oxygen under-saturated water does not determine a significant difference in the thermal response and egg development of specimens kept under well oxygenated condition (Baldanzi et al., 2020).

In the mangrove creek and mangrove fringe in Kenya, average water temperatures during the warmest part of the day range from 31 to $34^{\circ} \mathrm{C}$, at which $T$. crenata showed thermal metabolic insensitivity. At the higher temperatures recorded during the day in the seagrass meadow $\left(37^{\circ} \mathrm{C}\right)$, metabolism under $100 \%$ saturation declined, indicating the start of metabolic impairment. However, seagrass meadows are characterized by oxygen supersaturation that sustains metabolic rate at much higher temperatures compared to full and low oxygen saturation levels, revealing the important effect of oxygen supersaturation in modulating the metabolism of aquatic ectotherms in warm environments (Giomi et al., 2019; McArley et al., 2020).

\section{The Role of Dissolved Oxygen in Modulating Metabolic Rate}

Our data support that the level of dissolved oxygen regulates the thermal physiology of aquatic organisms (Pörtner, 2010) during acute diel (Giomi et al., 2019; Booth et al., 2021) and habitat-related fluctuations (Figure 5). Oxygen dynamics in coastal environments is often overlooked at fine temporal and spatial scale, yet oxygen varies on a daily basis and therefore aquatic ectotherm species are consistently exposed to fluctuating conditions (Taylor and Howes, 1994; Booth et al., 2021). Aquatic organisms that inhabit tropical coastal ecosystems, in which temperatures peak during daytime, benefit from the increased oxygen availability determined by enhanced photosynthetic activity of the primary producers 
(i.e., seagrasses, mangroves, microphytobenthos, and cyanobacterial mats) (Giomi et al., 2019).

These results expand our comprehension of the oxygendependent metabolic thermal response of aquatic animals. Aerobic metabolism is not only regulated in accordance with the temperature regime, but largely varies according with oxygen availability in water (Figure 5). Variation in aerobic metabolism and thermal tolerance in $T$. crenata is a function of dissolved oxygen; when water is undersaturated, its metabolism is lowered (possibly paralleled by a partial transition to anaerobic metabolism), becoming temperature independent. The increase of oxygen availability determines the rise of aerobic metabolism that peaks under conditions of oxygen supersaturation. When oxygen availability is above full saturation (100\%) and temperature causes changes in the rate of consumption the heat induces an increase of aerobic demand becomes fulfilled by oxygen supersaturation, which extends the thermal tolerance up to thermal extremes (Figure 5A). T. crenata may experience either a cyclical variation or a habitat-driven variation in aerobic metabolism in relation to environmental conditions (Figure 5B). Cyclical variation [as showed in Giomi et al. (2019) and Booth et al. (2021)] follows the fluctuation of dissolved oxygen due to the shift from primary production of the autotrophic organisms during the day to respiration of the whole community at night. Alternatively, habitatdriven variation occurs when animals move from microhabitats characterized by different levels of oxygen availability (examined in the present study; see also Mattone and Sheaves, 2017). The model in Figure 5 provides further explanation of the strategy adopted by aquatic eurytherms to modulate energy expenditure along the gradient of oxygen availability in heterogeneous fluctuating habitats.

The ability to modulate oxygen consumption rate reveals an evolutionary adaptation of aquatic animals to daily broad oxygen variation and explains their capacity to exploit a mosaic of different habitats characterized by significant differences in oxygen and temperature profiles over time (diel cycle) and space (spatial scale). This

\section{REFERENCES}

Alongi, D. M. (1990). Effect of mangrove detrital outwelling on nutrient regeneration and oxygen fluxes in coastal sediments of the central Great Barrier Reef lagoon. Estuar. Coast. Shelf Sci. 31, 581-598. doi: 10.1016/0272-7714(90) 90014-I

Altieri, A. H., Johnson, M. D., Swaminathan, S. D., Nelson, H. R., and Gedan, K. B. (2021). Resilience of tropical ecosystems to ocean deoxygenation. Trends Ecol. Evol. 36, 227-238. doi: 10.1016/j.tree.2020.11. 003

Andersen, M. R., Kragh, T., and Sand-Jensen, K. (2017). Extreme diel dissolved oxygen and carbon cycles in shallow vegetated lakes. Proc. Biol. Sci. 284:20171427. doi: 10.1098/rspb.2017.1427

Buchanan, K., Burt de Perera, T., Carere, C., Carter, T., Hailey, A., Hubrecht, R., et al. (2012). Guidelines for the treatment of animals in behavioural research and teaching. Anim. Behav. 83, 301-309. doi: 10.1016/j.anbehav.2011.10.031

Antão, L. H., Bates, A. E., Blowes, S. A., Waldock, C., Supp, S. R., Magurran, A. E., et al. (2020). Temperature-related biodiversity change across temperate marine and terrestrial systems. Nat. Ecol. Evol. 4, 927-933. doi: 10.1038/s41559-0201185-7 can unveil an underestimated mechanism of resilience to thermal stress of aquatic species that, by living at tropical latitudes, are actually considered more vulnerable to climate warning.

\section{DATA AVAILABILITY STATEMENT}

All data needed to evaluate the conclusions are present in the manuscript. Data can be requested from the authors.

\section{AUTHOR CONTRIBUTIONS}

FG and MF conceived the study, developed the conceptual framework, and set up and carried out the experiments. FG, DD, and MF analyzed the data and wrote the first draft of the manuscript. All authors contributed to the writing of the final version of the manuscript.

\section{FUNDING}

This study was supported by SP3-People (Marie Curie) IRSES Project CREC (No. 247514) and by KAUST through baseline funding to DD and the Competitive Research Grant (CRG7-3739) "The role of the bacterial symbiome at the gillwater (air) interface in the evolution toward terrestrialization (Microlanding)," 1 April 2019 to 31 March 2022. FG was funded by the Intra-European Fellowship (ex Marie Curie) number 221017, FP7.

\section{ACKNOWLEDGMENTS}

We thank Simone Babbini and Simone Baldanzi for their help during fieldwork and James Kairo for logistical support at the Kenyan Marine and Fishery Research Lab in Gazi and to Latifa's family for providing accommodation.

Atwood, T. B., Connolly, R. M., Ritchie, E. G., Lovelock, C. E., Heithaus, M. R., Hays, G. C., et al. (2015). Predators help protect carbon stocks in blue carbon ecosystems. Nat. Clim. Chang. 5, 1038-1045. doi: 10.1038/NCLIMATE 2763

Baldanzi, S., Storch, D., Fusi, M., Weidberg, N., Tissot, A., Navarrete, S., et al. (2020). Combined effects of temperature and hypoxia shape female brooding behaviors and the early ontogeny of the Chilean kelp crab Taliepus dentatus. Mar. Ecol. Prog. Ser. 646, 93-107. doi: 10.3354/meps13381

Bates, D., Mächler, M., Bolker, B. M., and Walker, S. C. (2015). Fitting linear mixed-effects models using lme4. J. Stat. Softw. 67. doi: 10.18637/jss.v067.i01

Bernhardt, J. R., O'Connor, M. I., Sunday, J. M., and Gonzalez, A. (2020). Life in fluctuating environments: adaptation to changing environments. Philos. Trans. R. Soc. B Biol. Sci. 375:20190454. doi: 10.1098/rstb.2019.0454rstb2019 0454

Booth, J., Fusi, M., Giomi, F., Chapman, E., Diele, K., and McQuaid, C. (2021). Diel oxygen fluctuation drives the thermal response and metabolic performance of coastal marine ectotherms. Proc. R. Soc. B Biol. Sci. 288:20211141.

Breitburg, D., Levin, L. A., Oschlies, A., Grégoire, M., Chavez, F. P., Conley, D. J., et al. (2018). Declining oxygen in the global ocean and coastal waters. Science 359:eaam7240. doi: 10.1126/science.aam7240 
Bridges, C., and Brand, A. (1980). Oxygen consumption and oxygen-independence in marine crustaceans. Mar. Ecol. Prog. Ser. 2, 133-141. doi: 10.3354/ meps002133

Brill, R. W., Bushnell, P. G., Elton, T. A., and Small, H. J. (2015). The ability of blue crab (Callinectes sapidus, Rathbun 1886) to sustain aerobic metabolism during hypoxia. J. Exp. Mar. Bio. Ecol. 471, 126-136. doi: 10.1016/j.jembe.2015.06.003

Cannicci, S., Dahdouh-guebas, F., Anyona, D., and Vannini, M. (1996). Natural diet and feeding habits of Thalamita crenata (Decapoda: Portunidae). J. Crustac. Biol. 16, 678-683. doi: 10.2307/1549188

Cooksey, K. E., and Cooksry, B. (1978). Growth-influencing substances in sediment extracts from a subtropical wetland: investigation using a diatom bioassay. J. Phycol. 14, 347-352.

Craig, H., and Hayward, T. (1983). Oxygen supersaturation in the ocean: biological versus physical contributons. Science 735, 1983-1986.

Das, T., and Stickle, W. B. (1993). Sensitivity of crabs Callinectes sapidus and C. similis and the gastropod Stramonita haemastoma to hypoxia and anoxia. Mar. Ecol. Prog. Ser. 98, 263-274. doi: 10.3354/meps098263

Dubuc, A., Baker, R., Marchand, C., Waltham, N. J., and Sheaves, M. (2019). Hypoxia in mangroves: occurrence and impact on valuable tropical fish habitat. Biogeosciences 16, 3959-3976. doi: 10.5194/bg-16-3959-2019

Ern, R., Huong, D. T. T., Phuong, N. T., Madsen, P. T., Wang, T., and Bayley, M. (2015). Some like it hot: thermal tolerance and oxygen supply capacity in two eurythermal crustaceans. Sci. Rep. 5, 10743. doi: 10.1038/srep 10743

Fishelson, L. (1971). Ecology and distribution of the benthic fauna in the shallow waters of the Red Sea. Mar. Biol. 10, 113-133.

Frederich, M., and Pörtner, H. O. (2000). Oxygen limitation of thermal tolerance defined by cardiac and ventilatory performance in spider crab, Maja squinado. Am. J. Physiol. Regul. Integr. Comp. Physiol. 279, R1531-R1538.

Fusi, M., Babbini, S., Giomi, F., Fratini, S., Dahdouh-Guebas, F., Daffonchio, D., et al. (2017). Thermal sensitivity of the crab Neosarmatium africanum in tropical and temperate mangroves on the east coast of Africa. Hydrobiologia 803, 251-263. doi: 10.1007/s10750-017-3151-1

Fusi, M., Giomi, F., Babbini, S., Daffonchio, D., McQuaid, C. D., Porri, F., et al. (2015). Thermal specialization across large geographical scales predicts the resilience of mangrove crab populations to global warming. Oikos 124, 784-795. doi: 10.1111/oik.01757

García-Rueda, A., Tremblay, N., Mascaró, M., Díaz, F., Paschke, K., CaamalMonsreal, C., et al. (2021). The thermal tolerance of a tropical population of blue crab (Callinectes sapidus) modulates aerobic metabolism during hypoxia. J. Therm. Biol. 1:103078. doi: 10.1016/j.jtherbio.2021.103078

Giomi, F., Barausse, A., Duarte, C. M., Booth, J., Agusti, S., Saderne, V., et al. (2019). Oxygen supersaturation protects coastal marine fauna from ocean warming. Sci. Adv. 5:eaax1814. doi: 10.1126/sciadv.aax1814

Hui, T. Y., Dong, Y., Han, G., Lau, S. L. Y., Cheng, M. C. F., Meepoka, C., et al. (2020). Timing metabolic depression: predicting thermal stress in extreme intertidal environments. Am. Nat. 196, 501-511. doi: 10.1086/710339

Kitheka, J. U., Ohowa, B. O., Mwashote, B. M., Shimbira, W. S., Mwaluma, J. M., and Kazungu, J. M. (1996). Water circulation dynamics, water column nutrients and plankton productivity in a well-flushed tropical bay in Kenya. J. Sea Res. 35 , 257-268. doi: 10.1016/S1385-1101(96)90753-4

Kroeker, K. J., Bell, L. E., Donham, E. M., Hoshijima, U., Lummis, S., Toy, J. A., et al. (2020). Ecological change in dynamic environments: accounting for temporal environmental variability in studies of ocean change biology. Glob. Chang. Biol. 26, 54-67. doi: 10.1111/gcb.14868

Long, M. H., Sutherland, K., Wankel, S. D., Burdige, D. J., and Zimmerman, R. C. (2020). Ebullition of oxygen from seagrasses under supersaturated conditions. Limnol. Oceanogr. 65, 314-324. doi: 10.1002/lno.11299

Marsden, I. D. (1979). Seasonal oxygen consumption of the saltmarsh lsopod Sphaeroma rugicauda. Mar. Biol. 51, 329-337. doi: 10.1007/BF00389211

Marshall, D. J., and McQuaid, C. D. (2011). Warming reduces metabolic rate in marine snails: adaptation to fluctuating high temperatures challenges the metabolic theory of ecology. Proc. Biol. Sci. 278, 281-288. doi: 10.1098/rspb. 2010.1414

Matthijs, S., Tack, J., Speybroeck, D., Van, and Koedam, N. (1999). Mangrove species zonation and soil redox state, sulphide concentration and salinity in
Gazi Bay (Kenya), a preliminary study. Mang. Salt Marsh. 3, 243-249. doi: 10.1023/A:1009971023277

Mattone, C., and Sheaves, M. (2017). Patterns, drivers and implications of dissolved oxygen dynamics in tropical mangrove forests. Estuar. Coast. Shelf Sci. 197, 205-213. doi: 10.1016/j.ecss.2017.08.028

McArley, T. J., Sandblom, E., and Herbert, N. A. (2020). Fish and hyperoxiafrom cardiorespiratory and biochemical adjustments to aquaculture and ecophysiology implications. Fish Fish. 22, 324-355. doi: 10.1111/faf.12522

Mcmahon, B. R. (1988). Physiological responses to oxygen depletion in intertidal animals. Integr. Comp. Biol. 28, 39-53. doi: 10.1093/icb/28.1.39

Pörtner, H.-O. (2010). Oxygen- and capacity-limitation of thermal tolerance: a matrix for integrating climate-related stressor effects in marine ecosystems. J. Exp. Biol. 213, 881-893.

Pörtner, H. O., and Giomi, F. (2013). Nothing in experimental biology makes sense except in the light of ecology and evolution. J. Evol. Biol. 216, 2771-2782.

R Core Team (2017). A Language and Environment for Statistical Computing. Vienna: R Foundation for Statistical Computing.

Rüppell, E. (1830). Beschreibung und Abbildung von 24 Arten kurzschwänzigen Krabben als Beitrag zur Naturgeschichte des rothen Meeres: Mit sechs Steindrucktafeln, Brönner.

Sheaves, M., Baker, R., Nagelkerken, I., and Connolly, R. M. (2015). True value of estuarine and coastal nurseries for fish: incorporating complexity and dynamics. Estuaries Coast. 38, 401-414. doi: 10.1007/s12237-014-9846-x

Sokolova, I. M., Frederich, M., Bagwe, R., Lannig, G., and Sukhotin, A. A. (2012). Energy homeostasis as an integrative tool for assessing limits of environmental stress tolerance in aquatic invertebrates. Mar. Environ. Res. 79, 1-15. doi: 10. 1016/j.marenvres.2012.04.003

Sokolova, I. M., and Pörtner, H.-O. (2003). Metabolic plasticity and critical temperatures for aerobic scope in a eurythermal marine invertebrate (Littorina saxatilis, Gastropoda: Littorinidae) from different latitudes. J. Exp. Biol. 206, 195-207. doi: 10.1242/jeb.00054

Taylor, C. D., and Howes, B. L. (1994). Effect of sampling frequency on measurements of seasonal primary production and oxygen status in nearshore coastal ecosystems. Mar. Ecol. Prog. Ser. 108, 193-203. doi: 10.3354/ meps108193

Terblanche, J. S., Hoffmann, A. A., Mitchell, K. A., Rako, L., Roux, P. C., and Chown, S. L. (2011). Ecologically relevant measures of tolerance to potentially lethal temperatures. J. Exp. Biol. 10, 3713-3725. doi: 10.1242/jeb.061283

Vannini, M., and Innocenti, G. (2000). Research on the coast of Somalia. Portunidae (Crustacea Brachyura). Trop. Zool. 13, 251-298. doi: 10.1080/ 03946975.2000.10531136

Verberk, W. C. E. P., Overgaard, J., Ern, R., Bayley, M., Wang, T., Boardman, L., et al. (2016). Does oxygen limit thermal tolerance in arthropods? A critical review of current evidence. Comp. Biochem. Physiol. Part A Mol. Integr. Physiol. 192, 64-78. doi: 10.1016/j.cbpa.2015.10.020

Vezzosi, R., Barbaresi, S., Anyona, D., and Vannini, M. (1994). Activity patterns in Thalamita crenata (Portunidae, Decapoda): a shaping by the tidal cycles. Mar. Freshw. Behav. Physiol. 24, 207-214. doi: 10.1080/10236249509378895

Conflict of Interest: The authors declare that the research was conducted in the absence of any commercial or financial relationships that could be construed as a potential conflict of interest.

Publisher's Note: All claims expressed in this article are solely those of the authors and do not necessarily represent those of their affiliated organizations, or those of the publisher, the editors and the reviewers. Any product that may be evaluated in this article, or claim that may be made by its manufacturer, is not guaranteed or endorsed by the publisher.

Copyright ( 2021 Fusi, Daffonchio, Booth and Giomi. This is an open-access article distributed under the terms of the Creative Commons Attribution License (CC BY). The use, distribution or reproduction in other forums is permitted, provided the original author(s) and the copyright owner(s) are credited and that the original publication in this journal is cited, in accordance with accepted academic practice. No use, distribution or reproduction is permitted which does not comply with these terms. 